Original Research Paper

\title{
Pelatihan Penggunaan Media Pembelajaran Berbasis Android Sebagai Sumber Belajar untuk Guru dan Peserta Didik
}

\author{
Agus Ramdani $^{1 *}$, A. Wahab Jufri ${ }^{1}$, Jamaluddin ${ }^{1}$ \\ ${ }^{\text {I} P r o g r a m ~ S t u d i ~ M a g i s t e r ~ P e n d i d i k a n ~ I P A, ~ P a s c a s a r j a n a, ~ U n i v e r s i t a s ~ M a t a r a m, ~ M a t a r a m, ~ I n d o n e s i a . ~}$
}

https://doi.org/10.29303/jpmpi.v3i2.1026

Sitasi: Ramdani, A., Jufri, A. W \& Jamaluddin. (2021). Pelatihan Penggunaan Media Pembelajaran Berbasis Android Sebagai Sumber Belajar untuk Meningkatkan Literasi Sains Peserta Didik. Jurnal Pengabdian Magister Pendidikan IPA, 4(4)

\section{Article history}

Received: 15 September 2021 Revised: 20 September 2021

Accepted: 27 September 2021

*Corresponding Author: Agus Ramdani, Program Studi Studi Magister Pendidikan IPA, Pascasarjana, Mataram, Indonesia. Email: aramdani07@unram.ac.id

\section{Pendahuluan}

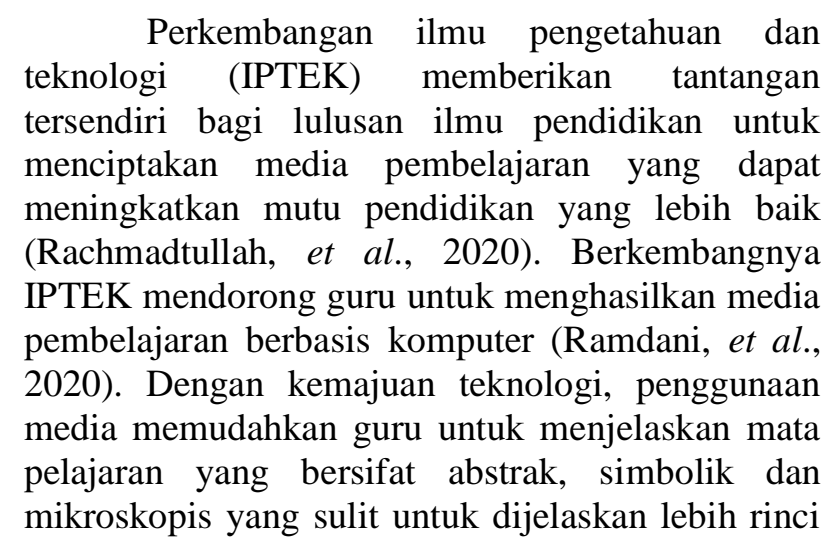

\begin{abstract}
Penggunaan media dalam pembelajaran dapat mengatasi keterbatasan pendidik dalam menyampaikan informasi maupun keterbatasan jam pelajaran di kelas. Permasalahan terkait media pembelajaran adalah belum maksimalnya pemanfaatan media sebagai sumber belajar dan masih banyak pendidik yang belum mengembangkan media pembelajaran, termasuk yang dialami oleh guru mitra. Tujuan pengabdian pada masyarakat yang dilakukan untuk memotivasi dan menfasilitasi tenaga pendidik agar mampu memanfaatkan smartphone sebgagai media pembelaran. Metode yang digunakan dalam pelatihan ini adalah ceramah, demonstrasi dan praktik. Teknik pengumpulan data menggunakan angket mengenai persepsi peserta terhadap pelaksanaan pelatihan. Indikator keberhasilan pelatihan ini meliputi tingkat pembelajaran, tingkat perilaku, tingkat reaksi dan tingkat hasil. Hasil yang diperoleh dari pengolahan data keseluruhan indikator adalah peserta setuju bahwa pelaksanaan pelatihan telah berjalan dengan baik, dimana sebagian besar peserta berpandangan bahwa pelaksanaan pelatihan telah memberikan manfaat yang mendalam dan sangat membantu dalam peningkatan kualitas diri peserta.
\end{abstract}

Keywords: Pelatihan, Media Pembelajaran, Android, Sumber belajar.

oleh buku ajar peserta didik (Yustiqvar, et al., 2019).

Guru masa depan yang diharapkan adalah sosok guru yang dapat mengembangkan IPTEK sebagai sumber belajar tambahan dalam pembelajaran serta sebagai tantangan untuk menghadapi abad 21 (O’Neal, et al., 2017). Salah satunya dengan mengembangkan media pembelajaran.

Berdasarkan hasil studi lapangan proses pembelajaran di sekolah ditemukan bahwa minimnya pemanfaatan media pembelajaran dalam kegiatan belajar mengajar. Hal ini mengakibatkan peserta didik kurang aktif dan kurang tertarik dengan materi yang diajarkan (Ramdani, et al., 
2020). Sementara itu, sekolah memiliki sarana dan prasarana yang memadai untuk menunjang pembelajaran, antara lain laboratorium komputer, laboratorium IPA dan LCD, tetapi penggunaannya belum maksimal (Hadisaputra, et al., 2019).

Perkembangan sistem operasi android, mulai dari gadget, tablet PC, smartphone dan aplikasi lain memiliki sistem operasi android lainnya. Penggunaan smartphone sendiri tengah populer di dunia dan tidak ketinggalan dengan Indonesia (Mahardini, et al., 2017). Dengan adanya smartphone dapat memberikan dampak yang sangat besar bagi kehidupan manusia dan memberikan banyak kemudahan dalam penggunaannya. Namun, penggunaan smartphone hanya dimanfaatkan untuk penggunaan sosial media saja dan hanya sebagian kecil yang memanfaatkannya untuk membantu kegiatan pembelajaran maupun pekerjaan manusia (Ramdani, et al., 2020). Saat ini sudah banyak aplikasi yang ditawarkan dalam satu genggaman sehingga lebih memudahkan dalam mencari informasi yang diperlukan.

Penggunaan media dalam pembelajaran dapat membantu keterbatasan pendidik dalam menyampaikan informasi maupun keterbatasan jam pelajaran di kelas (Budiyono, 2020). Media berfungsi sebagai sumber informasi materi pembelajaran maupun sumber soal latihan. Kualitas pembelajaran juga dipengaruhi oleh perbedaan individu peserta didik, baik perbedaan gaya belajar, perbedaan kemampuan kognitif, perbedaan kecepatan belajar, maupun perbedaan latar belakang (Yektiastuti \& Ikhsan, 2016).

Media pembelajaran dapat dibuat dan dirancang sesuai dengan perkembangan teknologi saat ini. Media pembelajaran berbantuan teknologi dan informasi (TIK) dapat digunakan untuk menjadikan pembelajaran menjadi menarik dan memberikan dampak yang positif terhadap performa akademik berupa motivasi belajar dan hasil belajar peserta didik (Chuang, 2014). Penggunaan media pembelajaran berbantuan TIK dapat membuat pembelajaran kimia menjadi lebih efektif (Sutrisno, 2011; Riyadi \& Pardjono, 2014).

Penggunaan media pembelajaran berbasis Android merupakan salah satu penerapan gaya belajar abad ke 21 (Calimag, et al., 2014). Penggunaan media pembelajaran sejenis ini berpotensi untuk membantu meningkatkan performa akademik peserta didik berupa hasil belajar pada ranah kognitif (Chuang \& Chen, 2007;
Jabbour, 2014) dan motivasi belajar peserta didik (Hess, 2014; Calimag et al., 2014). Sakat et al. (2012) menyebutkan implementasi pembelajaran menggunakan smartphone dan tablet dapat memberikan dampak positif terhadap dimensi kognitif, metakognitif, afektif, dan sosial budaya. Smartphone dan tablet memiliki kekuatan untuk mentransformasi pengalaman belajar. Media pembelajaran jenis ini memungkinkan peserta didik belajar tidak terbatas oleh waktu dan tempat dengan aplikasi yang menarik (Squire, 2009; Meister, 2011).

\section{Metode}

Pelaksanaan kegiatan pengabdian ini berlangsung dalam beberapa tahap sebagai berikut 1. Tahap persiapan.

2. Tahap pelaksanaan.

3. Tahap evaluasi.

Pelatihan penggunaan media pembelajaran berbasis android sebagai sumber belajar berdasarkan solusi dari permasalahan seperti yang telah diuraikan di atas membutuhkan metode pelaksanaan yang relevan. Beberapa metode yang digunakan adalah:

1. Sosialisai, pada tahap ini Tim mensosialisaikan tema program pada pihak sekolah. Metode yang digunakan adalah diskusi. Tujuan pada program sosialisai adalah untuk memperoleh pemahaman yang sama tentang pentingnya penggunaan teknologi pada abad 21, serta pemanfaatan teknologi merupakan salah satu solusi yang digunakan dalam pembelajaran jarak jauh pada saat masa pandemi Covid-19

2. Metode pelatihan untuk pelatih mitra (Training of Trainer) agar setelah selesai program pemngabdian mitra dapat melanjutkan. Dalam hal ini, materi terdiri dari empat bagian yang terdiri dari: (a) uraian yang menjelaskan tentang tahapan dalam pengoperasian media pembelajaran berbasis android, (b). bahan bacaan adalah materi bacaan yang dapat dijadikan referensi bagi fasilitator atau pelatih mengenai isi materi yang akan disampaikan dan (c) lembar kegiatan yang merupakan lembar aktivitas yang digunakan peserta dalam proses pembelajaran. Metode pelaksanaan pelatihan 
penggunaan media pembelajaran berbasis android menggunakan zoom meeting.

3. Focus Group Discussion (FGD) adalah metode yang digunakan berdasarkan relevansi tiap solusi, hal ini sangat penting untuk memperoleh informasi mengenai beberapa pertanyaan tentang bagaimana cara mengembangkan dan mengoperasikan media pembelajaran berbasis android.

\section{Hasil dan Pembahasan}

\section{Tahap Persiapan}

Agar kegiatan ini berjalan dengan lancar sesuai dengan apa yang direncanakan dan memenuhi tujuan serta target yang hendak dicapai, maka dilakukan kegiatan persiapan antara lain:

1. Mengadakan observasi terhadap objek sasaran, agar informasi yang diperoleh lebih memberikan gambaran yang jelas terhadap kegiatan yang akan dilakukan nantinya. Kegiatan ini merupakan koordinasi awal dengan pihak sekolah SMPN 9 Kota Mataram. Melalui wawancara dengan kepala sekolah dan beberapa guru diperoleh informasi tentang pemanfaatan komputer sebagai pendukung media pembelajaran. Selama ini guru-guru mangalami kesulitan dalam mengembangkan pembelajaran berbasis teknologi karena keterbatasan guru dalam mengikuti perkembangan teknologi. Selama ini, kebanyakan guru hanya menggunakan metode pembelajaran yang konvensional dalam memberikan pemahaman siswa terhadap materi pembelajaran. Hasil koordinasi dengan pimpinan sekolah, disepakati kegiatan dilaksanakan via zoom meeting.

2. Melaksanakan pertemuan/diskusi dengan anggota tim pelaksana pengabdian dan merumuskan langkah-langkah apa yang harus dilaksanakan terhadap kegiatan ini, termasuk juga dalam hal ini menetapkan persiapan perangkat pelatihan, materi pelatihan dan bentuk keterampilan yang akan dilakukan. Dari hasil koordinasi awal, tim pelaksana menyiapkan materi pelatihan dengan memperhatikan usulan dari kepala sekolah atau sesuai kebutuhan guru.

3. Penentuan peserta pelatihan yang terdiri dari seluruh guru yang berasal dari SMPN 9 Kota Mataram.
4. Kegiatan berikutnya adalah menetapkan materi pelatihan, yang terdiri dari pengenalan Adobe Flash, rancang bangun dan produksi media pembelajaran berbasis Android.

5. Menetapkan jadwal pelaksanaan kegiatan beserta susunan acara kegiatan pengabdian kepada masyarakat.

\section{Tahap Pelaksanaan}

Pelaksanaan pelatihan diawali dengan proses penyampaian materi terkait pentingnya penggunaan media pembelajaran sebagai sumber belajar. Dalam kegiatan ini, tim pelaksana melibatkan pendamping dan mahasiswa sebagai tutor. Kegiatan dilaksanakan dalam dua tahapan, yakni (1) tahapan pemberian materi mengenai pembuatan media pembelajaran berbasis android oleh 3 orang pemateri, dan (2) mempraktekan langsung materi yang telah diberikan guna meningkatkan pengetahuan dan pemahaman terhadap materi yang diberikan. Metode yang digunakan dalam penyampaian materi, baik yang bersifat teori maupun praktek adalah metode ceramah dan tanya jawab serta praktek langsung. Beberapa contoh kegiatan pelatihan penggunaan android via zoom meeting disajikan pada Gambar 1.

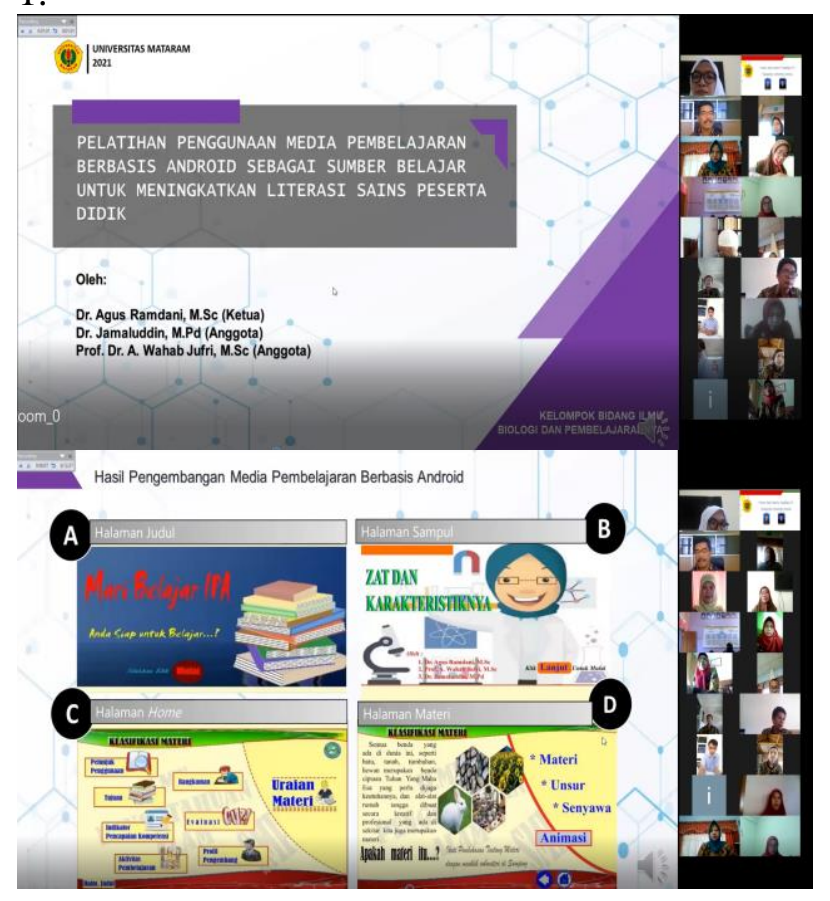




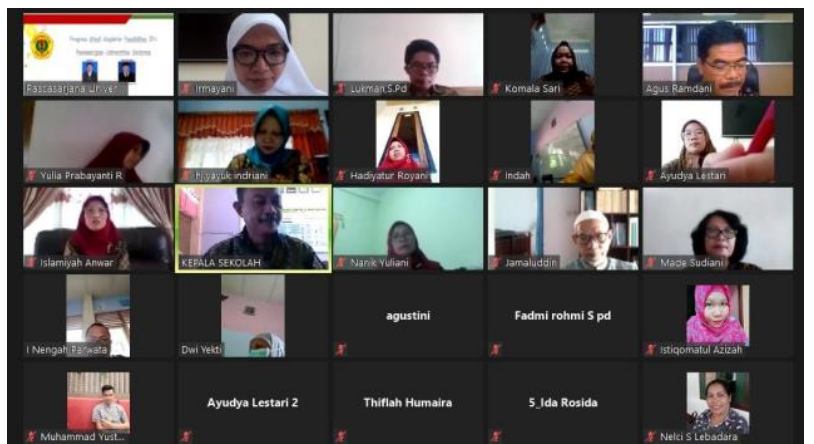

Gambar 1. Kegiatan pelatihan penggunaan media pembelajaran berbasis android.

Pada kegiatan pengabdian ini, guru dilatih untuk menggunakan aplikasi perangkat lunak Adobe Flash CS 6 yang dapat dioperasikan dalam memproduksi media pembelajaran berbasis android. Kegiatan yang dilakukan memberikan pandangan kepada guru tentang konsep pembalajaran dengan menggunakan android. Kumar Basak, et al (2018) menyatakan bahwa melalui aplikasi pembelajaran yang dikembangkan sesuai dengan konsep akan membantu siswa dalam melakukan pengukuran secara mandiri terhadap setiap konsep pembelajaran berbasis simulasi pelajaran.

Hal ini sependapat dengan pendapat Ramdani, et al (2020) media pembelajaran berbasis android dapat digunakan sebagai media pembelajaran bagi siswa SMP karena nilai rata-rata kelayakan menunjukkan bahwa penerapan tersebut layak, siswa dapat mempelajari materi zat dan karakteristiknya, dengan menggunakan aplikasi ini di smartphone mereka. Selain itu siswa juga dapat mengevaluasi ilmunya dengan mengikuti bagian quiz pada media android yang dikembangkan.

Media berbasis android ini memiliki kelebihan yaitu dapat digunakan secara mandiri baik di sekolah maupun di luar sekolah karena media ini mudah didapatkan cukup mengunduh melalui Google Drive maka dapat digunakan dengan praktis serta dapat diunduh melalui gadget atau melalui komputer. Media pembelajaran ini juga dilengkapi dengan pembahasan dan di akhir evalausi terdapat hasil skor penilaian untuk mengetahui tingkat pencapaian siswa dengan menggunakan media pembelajaran ini. Hal tersebut sesuai dengan penelitian dari Muyaroah \& Fajartia (2017) yang menunjukan bahwa pembelajaran berbasis android dapat meningkatkan hasil belajar peserta didik.
Saat mengikuti kegiatan pengabdian, seluruh peserta sangat antusias dalam melaksanakan berbagai instruksi yang diberikan oleh tim instruktur dari pengabdian. Hadisaputra, et al (2020) menyatakan bahwa pembelajaran dengan memanfaatkan media juga meningkatkan kreativitas siswa dan memberikan umpan balik yang berarti bagi pekerjaan siswa.

Saat pelatihan berlangsung juga diselingi dengan kegiatan Tanya jawab khususnya dalam permasalahan pendidikan, penerapan kurikulum. Berdasarkan hasil pengamatan selama kegiatan berlangsung, para peserta menyatakan tertarik dan sangat merasa perlu dengan kehadiran pelatihan yang telah diberikan karena melalui pelatihan pengmbangan media pembelajaran berbasis android para guru mndapatkan pembaruan dalam bidang teknologi informasi dalam pendidikan.

Dari hasil diskusi dengan para peserta kegiatan dan kepala sekolah, mereka sangat mengharapkan pelatihan-pelatihan yang dapat menunjang maksimalnya kegiatan pembelajaran seperti pelatihan yang telah dilaksanakan ini. Dengan banyaknya tuntutan dalam proses belajar mengajar, dimana guru harus dapat menciptakan suasana kelas yang aktif dan interaktif, para guru diharapkan dapat memanfaatkan kemajuan teknologi sebagai media pendukung dalam proses pembelajaran. Namun kegiatan ini diharapkan tidak berakhir sampai di sini, tetapi bisa berlanjut dalam bentuk kerjasama dalam pengembangan materi dan informasi tentang media pembelajaran menggunakan komputer.

\section{Kesimpulan}

Kegiatan Pengabdian kepada Masyarakat Program Kemitraan Masyarakat (PKM) ini sudah dilakukan berupa pelatihan pengembangan media pembelajaran berbasis android. Dengan kerjasama tim pengabdian yang baik dan peran serta aktif dari pemateri dalam kegiatan pengabdian ini maka semuanya telah berjalan sesuai yang diharapkan dan harapannya dapat memberikan manfaat bagi mitra pengabdian masyarakat yaitu para guru dalam mempersiapkan materi pembelajaran secara menarik dan interaktif. 


\section{Ucapan Terimakasih}

Terimkasih kami ucapkan kepada Rektor Universitas Mataram yang telah memberikan fasilitas berupa pendanaan untuk pelaksanaan pengabdian kepada masyarakat dapat berjalan dengan lancar. Selanjutnya ucapan terimakasih kepada Ketua LPPM, Direktur Pascasarjana, Pihak Sekolah SMPN 9 Kota Mataram, serta semua pihak yang tidak dapat kami sebutkan satu persatu yang telah banyak membantu kami dalam menyelesaikan pengabdian ini.

\section{Daftar Pustaka}

Budiyono, B. (2020). Inovasi Pemanfaatan Teknologi Sebagai Media Pembelajaran di Era Revolusi 4.0. Jurnal Kependidikan: Jurnal Hasil Penelitian dan Kajian Kepustakaan di Bidang Pendidikan, Pengajaran dan Pembelajaran, 6(2), 300-309.

Calimag, J. N., Mugel, P. A., Conde, R. S., \& Aquino, L. B. (2014). Ubquitous learning environment using android mobile application. International Journal of Research in Engineering \& Technology, 2(2), 119-128.

Chuang, T. Y., \& Chen, W. F. (2007). Effect of digital games on children's cognitive achievement. Journal of Multimedia, 2(5), 27-30.

Chuang, Y. T. (2014). Increasing learning motivation and student engagement through the technology-supported learning environment. Creative Education, 5, 19691978.

Hadisaputra, S., Gunawan, G. \& Yustiqvar, M. (2019). Effects of Green Chemistry Based Interactive Multimedia on the Students' LearningOutcomesand Scientific Literacy. Journal of Advanced Research in Dynamical and Control Systems, 11(7), 664-674

Hadisaputra, S., Ihsan, M. S., \& Ramdani, A. (2020, March). The development of chemistry learning devices based blended learning model to promote students' critical thinking skills. In Journal of Physics: Conference Series (Vol. 1521, No. 4, p. 042083). IOP Publishing.

Hess, S. (2014). Digital media and student learning: impact of electronic books on motivation and achievement. New England Reading Associatiion Journal, 49 (2), 35-39.

Jabbour, K. K. (2014). An Analysis of the effect of mobile learning on lebanse higher education. Informatics in Education, 13(1), 1-15.

Kumar Basak, S., Wotto, M., \& Belanger, P. (2018). E-learning, M-learning and Dlearning: Conceptual definition and comparative analysis. E-learning and Digital Media, 15(4), 191-216.

Marhadini, S. A. K., Akhlis, I., \& Sumpono, I. (2017). Pengembangan media pembelajaran berbasis android pada materi gerak parabola untuk siswa sma. UPEJ Unnes Physics Education Journal, 6(3), 38-43.

Meister, J. (2011). 2011: The Year of the media tablet as a learning tool. Proquest, 65 (4), 28-31. 13

Muyaroah, S., \& Fajartia, M. (2017). Pengembangan Media Pembelajaran Berbasis Android dengan menggunakan Aplikasi Adobe Flash CS 6 pada Mata Pelajaran Biologi. Innovative Journal of Curriculum and Educational Technology, 6(2), 22-26.

O'Neal, L. J., Gibson, P., \& Cotten, S. R. (2017). Elementary school teachers' beliefs about the role of technology in 21 st-century teaching and learning. Computers in the Schools, 34(3), 192206.

Rachmadtullah, R. M. S. Z., Ms, Z., \& Sumantri, M. S. (2018). Development of computer-based interactive multimedia: study on learning in elementary education. Int. J. Eng. Technol, 7(4), 2035-2038.

Ramdani, A., Jufri, A. W., \& Jamaluddin, J. (2020). Pengembangan Media Pembelajaran Berbasis Android pada Masa Pandemi Covid-19 untuk Meningkatkan Literasi Sains Peserta Didik. Jurnal Kependidikan: Jurnal Hasil Penelitian dan Kajian Kepustakaan di Bidang Pendidikan, 
Pengajaran dan Pembelajaran, 6(3), 433440.

Riyadi, S., \& Pardjono, P. (2014). Pengembangan multimedia pembelajaran matematika berbasis komputer untuk kelas VIII SMP. Jurnal Inovasi Teknologi Pendidikan, 1(2).

Sakat, A. A., Mohd Zin, M. Z., Muhamad, R., Ahmad, A., Ahmad, N. A., \& Kamo, M. A. (2012). Educational technology media method in teaching and learning progress. American Journal of Applied Sciences, 9(6), 874-888.

Squire, K. (2009). Mobile media learning: multiplicities of place. On the Horizon, 17 (1), 70-80.

Sumantri, M. S., \& Rachmadtullah, R. (2016). The effect of learning media and self regulation to elementary students' history learning outcome. Advanced Science Letters, 22(12), 4104-4108.

Sutrisno. (2011). Pengantar pembelajaran inovatif. Jakarta: Gaung Perkasa Press.

Wijaya, I., \& Rakhmawati, L. (2015). Pengembangan media pembelajaran AutoPlay media studio pada mata pelajaran perekayasaan sistem audio di SMK Negeri 3 Surabaya. Jurnal Pendidikan Teknik Elektro, 4(3).

Yektyastuti, R., \& Ikhsan, J. (2016). Pengembangan media pembelajaran berbasis android pada materi kelarutan untuk meningkatkan performa akademik siswa SMA. Jurnal Inovasi Pendidikan IPA, 2(1), 88-99.

Yustiqvar, M., Hadisaputra, S., \& Gunawan, G. (2019). Analisis penguasaan konsep siswa yang belajar kimia menggunakan multimedia interaktif berbasis green chemistry. Jurnal Pijar Mipa, 14(3), 135140. 